\title{
Health emergency management in Aotearoa New Zealand: Making sense of professional development
}

\author{
Denise Blake, $\mathrm{PhD}$ \\ Patricia Niland, $\mathrm{PhD}$ \\ David M. Johnston, PhD
}

\begin{abstract}
Objective: To explore how health emergency management (HEM) personnel make sense of professional development, such as education and training, in their everyday roles and responsibilities within an increasingly complex emergency management and disaster field.
\end{abstract}

Design: This in-depth qualitative study comprised of semistructured interviews with 10 Astearoa New Zealand HEM personnel from a range of healthcare professions, including emergency managers, nurses, clinical support, and paramedics. The thematic, datadriven approach was exploratory. The research identified inductively significant thematic concepts relating to professional development from the health emergency personnel's talk about their roles and responsibilities.

Results: The authors identified four themes relating to professional development in the participants' talk: test yourself under pressure; selling what we do; under the pump; and real stuff that actually makes a difference. These themes represent shared sensemaking about how the participants negotiated their professional development needs and the needs of others while performing their everyday roles and responsibilities.

Conclusions: Our findings support the production of local and contextually driven knowledge that highlights how HEM personnel discuss professional development as strengths, tensions, challenges, and knowledge gaps. These insights contribute to a broader understanding of what needs to be taken into account when developing competencies, skill sets, and training programs to promote professional development in an increasingly complex emergency management and disaster field.
Key words: emergency management, health professional, Aotearoa New Zealand, training, skill, competencies

\section{INTRODUCTION}

Health emergency management (HEM) personnel are integral to a country's emergency management infrastructure. They are tasked with ensuring healthcare services are prepared for an emergency and are operational during surge events. The complexity of HEM practice is embedded in technologically driven and interconnected communities that demand sophisticated warning systems, protections, and responses to disaster events. ${ }^{1,2}$ As a result, HEM personnel are required to have contemporary knowledge and fit for purpose strategies to support critical health infrastructure. Despite this, little is known about HEM personnel in Aotearoa New Zealand and the way in which they engage with education and training. To address this localized and context specific gap, this work explores how HEM personnel in Aotearoa New Zealand make sense of professional development in their everyday practices. Located in the Southwest Pacific Ocean, Aotearoa New Zealand does not share a border with any other country and has a population of approximately 4.89 million people. It extends across the Pacific "Ring of Fire" and thus, is at risk of harm from volcanic and earthquake activity. ${ }^{3}$ It also endures a range of other natural hazards, including cyclones, droughts, floods, and person-made hazards such as terrorism and disease.

Aotearoa New Zealand has a complex health structure which is overseen by a government agency, the Ministry of Health $(\mathrm{MoH})$. With a three tier health 
system, the primary level services attend to prevention, screening, diagnosis, treatment, education, and counselling and nursing and allied professionals providing ambulatory forms of care. ${ }^{4}$ The secondary and tertiary level includes public hospitals and specialists services that require referrals to access. ${ }^{4,5}$

The healthcare services with Aotearoa New Zealand have dedicated HEM personnel, as well as auxiliary healthcare stakeholders who take up the management and oversight of patient and public safety in a disaster event. This involves attending to patient needs, and protecting the health and safety of immediate colleagues, wider healthcare staff, and emergency personnel. HEM personnel work toward continuity of healthcare by producing emergency plans, supporting business continuity planning, engaging with communities and responding to an emergency. ${ }^{6}$ As with any field, professional development is the cornerstone of effective capability across people and healthcare services, but it requires a standard set of competencies that are reinforced by education, training, and exercises within accredited programs. ${ }^{7}$ As such, there have been global efforts to professionalize practices of emergency management through the development of core competencies and training programs to deliver those competencies. For instance, a review of relevant social science scholarship and contemporary practices in the European human threat and disaster crisis management field found that comprehensive training programs encompassed the following key competencies: "risk assessment, risk management, principles of planning and preparedness, the organization of command, control and decision-making, inter-organisational communication and coordination, public information, media relations, coping with stress and collective behaviour, trauma and recovery, litigation, and evaluation and learning." "(p456) However, Ingrassia et al. ${ }^{9}$ argue that European countries lacked a standardized competency-based training approach that worked to support a more professional disaster management workforce.

In the United States, the Federal Emergency Management Agency's (FEMA) Emergency Management Institute aims to improve emergency management competencies across all levels of government by providing training and education that targets specific needs while building preparedness, and encouraging people to be disaster ready. FEMA has identified a range of competencies that encompasses the interconnected and accelerated pace of the modern world in which emergency management is embedded. These competencies are nested within three categories-building relationships, building emergency management practitioners, and building the person. The competencies include leadership skills, scientific and systems literacy, critical thinking, and ethical practice. ${ }^{2}$ Further, specific programs have particular aims, for instance the Department of Public Administration at the University of Central Florida developed emergency management plans for homeland security programs, recognized the importance of organizational management, interdisciplinary problem-solving skills, leadership, networking and collaboration skills, environmental and community sensitive practices, proactive risk-based management, and critical decision-making. ${ }^{1}$ It was claimed that these strategies supported collaboration and networking within emergency management programs.

On a strategic level, Australian state and regional emergency management professionals called for training to be context specific and attend to current practice challenges. Training, in particular, needed to value the growing complexity of socio-political and environmental contexts (eg, climate change extremes), tensions between political drivers and operational realities, differing meanings and agendas for community resilience, measurement of practical outcomes, and negotiating social media. ${ }^{10}$ Gillardo et al. ${ }^{11}$ argued that research attests to the necessity of a common emergency management competency framework that ensures responsible, transparent, and performancebased professional ethics. Their systematic review of 38 papers identified that while a significant number of heterogeneous competencies have been produced, based mainly on health professionals in healthcare settings, there was a lack of consistent terminology and competency definitions.

In Aotearoa New Zealand, the 2009 Civil Defence Emergency Management (CDEM $)^{12}$ framework constructed emergency management professionalism by 
outlining evidence-based and measurable emergency management competencies. ${ }^{13}$ These included leadership, relationship management, communication, capability development, information management, risk management, implementation, and planning. Although on the surface, these competencies appear appropriate, developing them can be problematic. A recent ministerial review of the Aotearoa New Zealand national emergency management system found that training and professional development was "very patchy [with] no required professional standards or accreditation."14(p3),15 The review noted that within organizations key emergency management roles were mostly part-time and consequently, emergency management responsibilities were not a priority. There was no clear emergency management career pathway with professional standards and accreditation, and there was no assurance that emergency management personnel had the training necessary to respond adequately to an emergency event. This review repeated earlier findings by the Ministry of Civil Defence and Emergency Management (MCDEM) ${ }^{16}$ where the number of professional development programs for Aotearoa New Zealand CDEM groups was unacceptably low and that only half of CDEM groups had a formal professional development strategy.

A 2014 qualitative study of a cross-section of national and local CDEM staff within Aotearoa New Zealand found that while 80 percent had received some professional development training, 20 percent reported no training or education. Insufficient leadership or management focused courses that could help to develop a robust CDEM framework was also a consistent theme. ${ }^{17}$ Thus, it was recognized that while the emergency management profession is relatively recent, more ongoing formalized training and education is crucial for emergency managers across all fields. ${ }^{6,14}$

Emergency management is a complex field that necessitates professional development education and training based on "fit for purpose" competency-based skills. However, there are challenges to developing context-specific professional skills as demonstrated by American, European, and Aotearoa New Zealand efforts to build and implement a common competency framework and accredited training programs. These gaps have arisen as emergency management evolves to meet the demands of globalized and technologically savvy societies that demand sophisticated risk assessments, warnings systems, response, recovery, and resiliency based approaches to emergency events. Within this context, our qualitative study explores how Aotearoa New Zealand emergency management personnel, working specifically within a health context, make sense of their professional development and roles and responsibilities.

\section{RESEARCH DESIGN}

This in-depth qualitative research draws on an interpretive perspective that understands that social realities are achieved mainly through shared practices in socio-historical locations. ${ }^{18}$ In this sense, language is understood and taken up as a social medium that enables shared meanings and, as we use language purposively, a social tool that constitutes social experiences. ${ }^{19}$ This work focused on Aotearoa New Zealand HEM personnel's talk concerning the way in which they made sense of their professional development in relation to their roles and responsibilities; although drawing from experiences in Aotearoa New Zealand, this work also contributes to wider understandings about the practices of HEM. It specifically questioned what enabled and constrained HEM personnel within their everyday emergency management practices. To do this, we asked the participants to talk about their everyday experiences and practices during one to one semistructured interviews. Our focus on their own socially produced interpretations in this context meant that an inductive thematic analysis ${ }^{20,21}$ was an appropriate method to use. This data-driven approach enabled inductive identification of significant thematic concepts relating to professional development within HEM personnel's talk about their roles and responsibilities.

\section{Procedure}

Potential participants were selected using a purposeful sampling method that identified any HEM personnel. A recruitment email was sent through the Aotearoa New Zealand MoH emergency management network. Interviews were conversational but semistructured and covered topics such as length of 
practice, training, role as a health emergency worker, what frameworks or guides they drew on, how they applied the National Health Emergency Plan, ${ }^{7}$ business continuity planning, managing media, engaging communities, working with vulnerable groups, evacuation planning, and what they needed to fulfill their roles better. Interviews averaged 60 minutes in length; they were audio-recorded and transcribed verbatim. Transcribed texts were organized for readability, while superfluous words and sounds such as "you know," "I guess," "kind of," and "um" were removed for readability. The institution's Human Ethics Committee approved the project as not posing any harm to the participants and low risk ethics was granted (4000017830).

\section{Participants}

Ten participants took part in the study and worked in a range of HEM roles. Their titles included health protection officers, emergency management coordinators, emergency planning managers, emergency managers, clinical support managers, duty nurse managers, and paramedics. The sample represented a range of relevant HEM personnel and covered a variety of disciplines and expertise. All participants had worked in healthcare in an emergency management role for a number of years and presented as conscientious and steadfast professionals. They were located predominantly in the lower part of the North Island of Aotearoa New Zealand. While drawing on an interpretive approach, this research does not attempt to generalize findings but offer insights into everyday experience.

\section{Analysis}

Using NVivo 11 software, our inductive thematic analysis ${ }^{21}$ data were grouped into 79 specific codes. These codes were then discussed within the research team and conceptually merged into 27 larger themes, which were considered in relation to each other and the research aims. Further refinement occurred and four critical themes identified.

\section{Findings}

The four themes relate to professional development in our HEM personnel's talk: training strengths; training challenges; training pressure; and training needs. These themes signify the shared meanings that participants drew on to make sense of, and negotiate, their training needs to perform their roles and responsibilities. The first theme identifies training that was constructed as valuable by participants. The second theme represents the participants articulated tensions and challenges to achieve training goals, and third theme highlights time pressures and stressful work schedules. The fourth theme is the participants' talk about knowledge and skill gaps. These themes are described using quotes as exemplars of particular points.

Training strengths: "Test yourself under pressure." The HEM participants identified two forms of emergency management training that supported their roles and responsibilities: course-based education and on the job practical exercises. All but one participant identified a recent health emergency course run by Massey University as useful because it contained basic information about emergency management theories and systems. They also valued the interdisciplinary perspectives they gained from interacting with other participants on the course. The following excerpt demonstrates this point:

... the people in the Armed Forces within the course ..., come from a different focus really, which is fantastic. It was great having them in the course. It made me realise what they have got in place. (Participant 6)

The value of collegial connection and gaining perspectives "from a different focus" was also attributed to engaging in person with other HEM personnel ("I'd rather sit with someone and talk about it ... and I get that's the way to do it," Participant 8). Other benefits from attending this type of course included having emergency management experts and practitioners sharing knowledge, and learning about emergency management contexts more generally ("It's just having scenarios and people coming to talk and just keep you up to date with any changes. What's out there. What they are doing," Participant 6). 
While course-based training was useful, the participants in this study were unanimous in their view that practical exercise-based training is superior to classroom-based training. The following excerpt demonstrates this:

... one of the things I found the most value in over the years has been more scenariobased training exercises . . . where you get a chance to really test yourself under pressure. . . . the feedback we get from our exercises is always better than the feedback we get from just our face to face classroom sessions ... and the other thing it tends to do is shake out things that are not quite right and it gives us a chance to tweak our plans and procedures and make little changes that make sense better next time around. (Participant 7)

The usefulness of exercise-based training is that HEM personnel get to test their capabilities "under pressure" in a simulated real-world situation, and to "shake things out"-adapting plans and responses to various emergency situations. Often this type of training is conducted in-house, giving participants handson experience while engendering confidence in their ability to perform effectively:

.. . the reason [the organisation] was so good at responding to emergencies, whether large or small, was because of the practices - every couple of weeks we got a small incident management team together to deal with something. (Participant 9)

So it was my first experience of coordinating different agencies together, Public Health, Fire Service and the Police, and Civil Defence ... that was a taster into establishing links and relationships, and what these people actually do . . . my confidence increased and talking to these people at a different level to what I was used to. (Participant 10)
Through scenario-based exercises, participants were able to develop the skills necessary to perform emergency management roles and respond efficiently. This form of real-world training was favored highly as it facilitated networking links with the broader HEM community; a necessary competency in a multidisciplinary field. HEM personnel valued coursebased and exercise-based training, suggesting that professional development is enhanced by using both educational mediums. Alongside their talk about the strength of professional development, the participants also represented the tensions and challenges they have experienced when trying to achieve professional development with other healthcare staff in emergency management planning. In the next theme, we discuss the pressures that hindered the participants capacity to share their knowledge.

Training challenges: "Selling what we do." HEM personnel are responsible for training other healthcare personnel in emergency management strategies. For the HEMs in this study, this included imparting knowledge about policies and practices to ensure service continuity, while also convincing people that emergency management is a valid and necessary skill to learn. As one participant stated, this role was about "selling what we do" (Participant 4). To advocate for emergency planning participants reported they had to communicate clearly the importance of having a collective and integrated emergency management approach, that is, it is "everybody's job" to be disaster ready:

One of my initiatives has been to highlight emergency management across the [organisation], so since I've been in this role I've set up groups to meet on a regular basis . . . to make sure that everybody knows emergency management is their job. (Participant 1)

As part of promoting a collaborative approach, participants talked about the challenge of consistently engaging others and continuously reinforcing the importance of being emergency and disaster ready. Some participants stated that as trainers they had to 
remain enthusiastic and committed so that their message remained "fresh" and "interesting." Without this, it is problematic for both teachers and students:

You wouldn't want people to get stale, so you have to keep repeating that message, and we're the ones that get bored repeating the message, but we still have to keep repeating it. We have to make it interesting for the people who have heard it before ... that's a training sort of thing, that's how you balance out training - different people present in different ways. I think you need humour, cos these people have heard this shit all the time, and then just some key messages. (Participant 8)

Repeating the same message can be tedious, as one of the participants above describes. However, diversity in the training role did help to resist this boredom. For many of the HEM personnel, training staff ranged from new staff orientation seminars to talking to all tiers of operational staff, including support staff, front-line staff, nursing staff, and doctors:

So when people start at the [service] they do a day of generic orientation, and part of that is an emergency management presentation and fire, so we give them safety instructions and things like that, and try and get them prepared for earthquakes and things like that. (Participant 8)

... there's a group of staff in the middle, so we do a lot of training for front-line staff, you know, mainly nurses, but the support services as well and some of the doctors and things like that, and we do quite a bit of training for the senior management team, the CEO and that, and there's this chunk of country in the middle, the service leaders. (Participant 7)

To teach emergency management to a diverse audience is challenging, not to mention time and resource consuming. This challenge was highlighted by Aotearoa New Zealand's MCDEM ${ }^{16}$ who reported that training is problematic because of time investments, efforts to develop new and engaging training programs, engaging senior management and staff to release staff for training, and the unwillingness of staff to be involved. Further, this report noted that emergency management officers are "not necessarily 'trainers' [so] many are being asked to step outside their comfort zone."16(p29) It is notable that this report refers to training emergency management personnel specifically, whereas our participants taught others within their organizations.

Alongside this challenge is the complex relationship between emergency management practices and the three-tiered healthcare system in Aotearoa New Zealand. The health system is made up of primary care, such as general practitioners, hospital care, public health services, aged care, and non-governmental healthcare provision. ${ }^{5}$ In effect, the field of healthcare and emergency management is "a complicated beast" as one participant articulated:

It's a massive area . . . very diverse and complicated. I know when I'm trying to train or talk to other people . . it doesn't help that it's quite a complicated beast ... . with all these different agencies involved and different Ministries, so some sort of basic orientation might be quite useful on how everything weaves together. (Participant 1)

This "weaving together" should begin with knowing that HEM is governed by a range of documents mandated by the MCDEM and the MoH, such as the MCDEM Act ${ }^{22}$ and the National Health Emergency Plan. ${ }^{7}$ There are also internal organizational policies and guidelines and those of external stakeholders that have implication for practice. For the participants, basic training about key legislation, policies, and guidelines is necessary for knowing how to navigate the complex structures. Additionally, each organization has a unique culture and approach to emergency management that 
requires negotiation by the HEM. Ethical and robust practice, in any field, involves ongoing professional development; however, another tension expressed by the participants concerned their professional development which is elaborated on in the ensuing theme.

Training pressure: "Under the pump." While this research found that the HEM personnel valued ongoing education and felt supported by senior management to have professional development training, the idiom "under the pump" represents how they experienced time constraints and busy work schedules. In much the same way, the $\mathrm{MCDEM}^{16}$ argued that emergency managers generally have good development opportunities via conferences, workshops, courses, exercises, and emergency management-related professional qualifications; although attending such courses is intermittent, as recognized by the Ministerial Review. ${ }^{14}$ The participants talked about the challenge of not having clear career trajectories and not having time to attend professional development courses that would strengthen their ability to enact roles and responsibilities. Many of the participants, especially those where emergency management roles were additional to their everyday responsibilities reported gradually obtaining knowledge on the job through hands-on experience and doing whatever emergency management courses they could attend or that were available:

I just continued plodding along really, and . . . I just sort of picked it up . . . there's still lots I don't know though. It was a pretty big, overwhelming thing [to learn health emergency management skills]. (Participant 10)

. . . it's only when talking to somebody else you sort of think, oh, I have learnt something. I have picked some things up. It's been a self-taught slow process I guess. (Participant 1)

Thus, despite senior management support for professional development, some HEM personnel faced the challenge of coming to grips with the "pretty big, overwhelming thing" and felt largely "self-taught" in the HEM field. When training was available, some participants experienced tension attending given they were fully occupied in their everyday roles. One participant said they had received less training in their HEM role than any other role:

So effectively I've had the least professional development I've ever had in this role than any other. Now so because I've been really busy in this role and I've got no time previously. I've not even had the chance to sort of reflect on what development I need or what I could do . . . I don't know if that's because I've just been that under the pump here that I've just been getting on with it and just doing it type thing. (Participant 2)

As well as a lack of time for their training, the participants delineated that it was problematic to identify what training to pursue ("what development I need or what I could do," Participant 2). An impediment to their professional development was demonstrated particularly in their responsibility to train their staff about emergency readiness and response. One participant highlighted this dual training role within his organization:

There's been some internal knowledge and previous plans, but at the time when I stepped into this role we lost staff, so some of our institutional knowledge went as well. It's been a bit of the blind leading the blind and just coming across things and trying to get to grips with everything, and then as soon as I'm a bit more up to speed, I try and pass that knowledge on to other team members. (Participant 1)

This challenge reflects Fogarty's ${ }^{17}$ finding that Aotearoa New Zealand emergency management personnel need strong leadership to champion professional development, particularly while enduring 
financial and time constraints in their everyday core roles and responsibilities. This was supported in our participants' talks about a lack of time (and skill) to train healthcare personnel within their organizations and broader healthcare domain and peruse their professional development. A search of the international emergency management professional development literature on competencies and training programs did take emergency managers everyday responsibilities into account. While some participants were unsure about what training to pursue, others identified areas that would enhance their abilities, roles, and responsibilities. Our next theme expands on this.

Training needs: "Real stuff that actually makes a difference." Some of the HEM personnel in this research talked about areas that would be useful for them to perform their roles and responsibilities more effectively. They identified training needs to address the knowledge gaps and skills required to do their jobs. As previously highlighted, with complex and diverse roles and responsibilities, HEM personnel want practical exercises to help them to perform appropriately in emergency events. The following participant critiqued an Aotearoa New Zealand emergency management course, and stated what they would prefer to learn about:

... I think the emergency management [course] is far too focused on Civil Defence disasters, to Civil Defence needs. I think you could turn emergency management into something far more than emergency management. It could be incident management or . . . whatever you want to call it, but there should be something around business continuity in there. There should be . . . a small paper on media management, or media engagement but it was a very limited choice .... (Participant 4)

This need to broaden the scope of emergency management training beyond a response-focused civil defence approach that reflects the evolving ethos of emergency management as a more complex field of practice within a globalized and socially integrated world. ${ }^{1}$ The skills in "business continuity" and "media management, or media engagement" signify the need to equip emergency management personnel with the skills to operate within this demanding context. As well as course-based and exercise training, it was clear that the participants valued real-world experience over theoretical perspectives as a knowledge base to draw on in a classroom setting:

It's because . . . , being able to take all the experiences over the years and being able to tell stories about real stuff that actually makes a difference to the students .... It's not all theory, this is actually what's happened .... You need stories to engage, and stories are things that allow us to put a human side to what we're talking about rather than it just being theoretical book stuff. (Participant 9)

The need to harness real-world emergency management experience accords with international "lessons learned" literature whereby actual disaster experiences are used to develop and fine-tune emergency management plans and programs (eg, see 22-24). Further, this knowledge is invaluable as it empowers emergency personnel to apply their competencies practically during disaster operations. ${ }^{1}$

The participants' focus on "real stuff," the experiences of emergency managers in the real-world rather than just "theoretical book stuff" was seen in the practical skills the participants identified as useful for their capability to perform their roles and responsibilities. As recognized above, media training was high on the list of such skills:

... we have media training ... where we learned how to provide what information we should supply to the media and of course the Privacy Act limits us considerably around that stuff, so it's important that you understand that information. It's also really good for us to understand that, well, with our media training we have media people come in who are reporters who say 
this is what we're after, and this is how we will track you. This is how we will get the information out of you. (Participant 9)

I mean, I'd love for the communications person to come to our DHB and talk to our COMS team on communicating during a crisis, and learning how to deal with politicians and dealing with the media and things like that because there's just so much knowledge that we could tap into. (Participant 10)

The skill to manage "how we will get information out of you" represents the importance of sharing appropriate information with the public. Being media savvy was an important training need given the instant accessibility and nonfiltering of social media information.

The need to engage in the broader sphere- world of emergency management"-was also talked about as a way to gain more knowledge. For example, the following participant argued that more input from the government is needed:

It would be great to get more engagement from the Ministry [of Health] at the DHB (district health board) level, like to have speakers, people someone from COMS [Communications]. We've got somebody that does the work that specialises in Pandemics and Infectious Disease, having someone like that come to the DHB to talk about their role and things like that to increase people's knowledge and interest in things that are happening in the world of emergency management. (Participant 10)

The "world of emergency management" suggests a need to not only train in specific competencies and skill sets but to also engage in the broader knowledge that might contribute to everyday emergency management practice as a professional endeavor. For the HEM personnel in this research, having a defined career path, while being recognized as a profession, and increasing the "big picture" context would strengthen the way in which they take up their roles and responsibilities.

\section{IMPLICATIONS}

Our qualitative study aimed to explore how Aotearoa New Zealand HEM personnel made sense of their and others professional development in their everyday roles and responsibilities. We identified strengths, tensions, challenges, and knowledge gaps.

A current training strength (test yourself under pressure) was that course-based training was useful yet the participants were unanimous that practical exercise-based training was a superior way to develop emergency management expertise. The European human threat and disaster crisis management field also called for emergency management professional development to be a combination of "conventional lectures, case study analyses, joint scenario development, role-playing simulations and full-scale exercises." ${ }^{(p 456)}$ In this sense, professional development would benefit from balancing the theoretical with the practical to enable effective competency skills.

A challenge for our participants was the need to champion emergency management skills (selling what we do) and to educate all healthcare staff in emergency management principles and procedures within their organizations and health areas. It is notable that our search for international and scholarly literature did not identify pressure to champion emergency management in their organizations. This advocating, as well as awareness raising and training of other nonemergency management staff takes time, resource, and a particular set of skills. Currently, there is limited training in this area.

Another primary challenge for professional development was the lack of time to conduct training given the busyness (under the pump) of everyday roles and responsibilities. This challenge reflects Fogarty's ${ }^{17}$ finding that Aotearoa New Zealand emergency personnel needed strong leadership to promote professional development particularly in the face of resources and time constraint tensions. Further, as our HEM participants identified, there is a challenge to pursue their professional development. It is notable 
that we did not determine this finding in our international emergency management and professional development literature search, suggesting a need to focus on how these everyday time and resource pressures could be managed more effectively.

Gaps in knowledge and skills (real stuff that actually makes a difference) were identified, representing the need to negotiate the increasing political, social, and technological complexity of our everyday world. Australian emergency managers cited information systems and social media as a challenge in their roles because they reduced the quality, and increased the variability in messaging. ${ }^{10}$ As well as media training, that HEM personnel need to learn how to "deal with politicians" suggests a knowledge gap in negotiating the political dynamics of disaster preparedness and response. As asserted by Bosomworth et al. ${ }^{10}$ it is important to have the skills to negotiate the tensions between political drivers and operational realities. It was proposed that socio-political knowledge could be gained by secondments to ministerial offices and courses in leadership diplomacy. Omitted from both the professional development literature and participants' talk were notions of cultural competency and the specificity of community engagement. Understanding that historical and social locations impact on how people learn, while valuing communities as heterogeneous will produce emergency management training and initiatives that shift across a multiagency approach. ${ }^{25-27}$

Overall, it is recognized that emergency management has evolved, particularly over the last decade, into a more complex field requiring professional development (education and training) based on consistent competency-based skill sets and terminology. It is also recognized that the people working in the HEM space are committed, hardworking, and diligent professionals. As a profession, emergency management needs to expand to meet the demands of globalized and technologically interconnected societies, that necessitate more sophisticated risk assessments, warnings systems, protections, and responses to disaster events. Our qualitative study identified that the HEM personnel in this study made sense of their professional development as strengths, tensions, challenges, and knowledge gaps. As such, these Aotearoa New Zealand insights contribute to a broader understanding of what enables and constrains the professionalization of HEM.

\section{ACKNOWLEDGMENT}

This research was support by the Massey University Research Fund: 1000019333.

Denise Blake, PhD, Senior Lecturer, Joint Centre for Disaster Research, Massey University, Wellington, Aotearoa New Zealand.

Patricia Niland, PhD, Academic Researcher, Joint Centre for Disaster Research, Massey University, Wellington, Aotearoa New Zealand.

David M. Johnston, PhD, Professor, Director, Joint Centre for Disaster Research, Massey University, Wellington, Aotearoa New Zealand.

\section{REFERENCES}

1. Kapucu N: Developing competency-based emergency management degree programs in public affairs and administration. J Public Aff Educ. 2011; 17(4): 501-521. doi:10.1080/15236803.201 1.12001659

2. Feldmann-Jensen S, Jensen S, Maxwell Smith S: The next generation core competencies for emergency management professionals: Handbook of behavioral anchors and key actions for measurement. 2017. Available at https://training.fema.gov/hiedu/ docs/emcompetencies/final_\%20ngcc_and_measures_aug2017.pdf. Accessed September 25, 2018.

3. GNS Science: The geology of New Zealand. 2018. Available at https://www.gns.cri.nz/Home/Our-Science/Earth-Science/RegionalGeology/The-Geology-of-New-Zealand. Accessed November 3, 2018. 4. Ministry of Health: Primary health care. 2018. Available at https://www.health.govt.nz/our-work/primary-health-care. Accessed November 1, 2018.

5. Ministry of Health: Overview of the health system. 2018. Available at https://www.health.govt.nz/new-zealand-health-system/ overview-health-system. Accessed March 1, 2018.

6. Ministry of Health: National health emergency plan: A framework for the health and disability sector. 2015. Available at https:// www.health.govt.nz/publication/national-health-emergency-planframework-health-and-disability-sector. Accessed June 10, 2018.

7. Ministry of Health: National health emergency plan. 2015. Available at https://www.health.govt.nz/our-work/emergency-man agement/national-health-emergency-plan. Accessed March 25, 2018. 8. Hart P, Sundelius B: Crisis management revisited: A new agenda for research training and capacity building within Europe. Coop Confl. 2013; 48(3): 444-461. doi:10.1177/0010836713485711.

9. Ingrassia PL, Foletti M, Djalali A, et al.: Education and training initiatives for crisis management in the European Union: A webbased analysis of available programs. Prehosp Disaster Med. 2014; 29(2): 115-126. doi:10.1017/S1049023X14000235.

10. Bosomworth B, Owen C, Curnin F: Addressing challenges for future strategic-level emergency management: Reframing, networking, and capacity-building. Disasters. 2017; 41(2): 306-323. doi:10.1111/disa.12196.

11. Gillardo AR, Djalali A, Foletti M, et al.: Core competencies in disaster management and humanitarian assistance: A systematic review. Disaster Med Public Health Prep. 2015; 9(4): 430-439. doi:10.1017/dmp.2015.24. 
12. Ministry of Civil Defence \& Emergency Management: Civil Defence Emergency Management Competency Framework. Technical Standard for the CDEM Sector [TS 02/09]. Wellington, Aotearoa New Zealand: Ministry of Civil Defence \& Emergency Management, 2009. Available at www.civildefence.govt.nz. Accessed October 25, 2018.

13. Lee B: Working together, building capacity: A case study of civil defence emergency management in New Zealand. J Disaster Res. 2010; 5(5): 565-575.

14. Department of the Prime Minister and Cabinet: Ministerial Review: Better Responses to Natural Disasters and Emergencies. Wellington, New Zealand: Ministry of Civil Defence \& Emergency Managment, 2017.

15. Ministry of Civil Defence \& Emergency Management: Wellington Earthquake National Initial Response Plan: Supporting Plan [SP 02/17]. Wellington, Aotearoa New Zealand: Ministry of Civil Defence \& Emergency Management, 2017. Available at https://www.civil defence.govt.nz/cdem-sector/cdem-framework/guidelines/wellingtonearthquake-national-initial-response-plan/. Accessed June 8, 2018.

16. Ministry of Civil Defence \& Emergency Management: CDEM Capability Assessment Report: Part 2. Wellington, New Zealand: Ministry of Civil Defence \& Emergency Management, 2012.

17. Fogarty ST: Exploring New Zealand's Capability to Strategically Manage Logistical Responses to Major Civil Defence and Emergency Management Events [master's thesis]. Palmerston North, New Zealand: Massey University, 2014. Available at $h t t p: / / h d l . h a n d l e . n e t / 10179 / 5815$. Accessed July 1, 2018.

18. Burr V: Social Constructionism. 2nd ed. New York, NY: Routledge, 2003.
19. Bruner J: Acts of Meaning. Cambridge, MA: Harvard University Press, 1990.

20. Braun V, Clarke V: Using thematic analysis in psychology. Qual Res Psychol. 2006; 3(2): 77-101. doi:10.1191/1478088706qp063oa. 21. Hayes N: Doing Psychological Research. Buckingham, UK: Open University Press, 2000.

22. Hsu E, Jenckes M, Catlett C, et al.: Effectiveness of hospital staff mass-casualty incident training methods: A systematic literature review. Prehosp Disaster Med. 2004; 19(3): 191-199. doi:10.1017/S1049023X00001771.

23. Rojek A, Little M: Review article: Evacuating hospitals in Australia: What lessons can we learn from the world literature? Emerg Med Australas. 2013; 25: 496-502. doi:10.1111/17426723.12160 .

24. Skryabinaa E, Reedyb G, Amlôta R, et al.: What is the value of health emergency preparedness exercises?. A scoping review study. Int J Disaster Risk Reduct. 2017; 21: 274-283. doi:10.1016/j. ijdrr.2016.12.010

25. Blake D, Lyons A: Opioid substitution treatment planning in a disaster context: Perspectives from emergency management and health professionals in Aotearoa/New Zealand. Int $J$ Environ Res Public Health. 2016; 13(1122): 2-14. doi:10.3390/ijerph13111122.

26. Blake D, Marlowe J, Johnston D: Get prepared: Discourse for the privileged? Int J Disaster Risk Reduct. 2017; 25: 283-288. doi:10.1016/j.ijdrr.2017.09.012.

27. Naser-Hall E: The disposable class: Ensuring poverty consciousness in natural disaster preparedness. DePaul J Soc Justice. 2013; 7(1): 55-86. 